\title{
Correction to: Discovery of a Novel Gene Conferring Tellurite Tolerance through Tellurite Reduction to Escherichia coli Transformant in Marine Sediment Metagenomic Library
}

\author{
Madison Pascual Munar ${ }^{1} \cdot$ Hirokazu Takahashi $^{2} \cdot$ Yoshiko Okamura $^{1,2}$ (D) \\ Published online: 9 November 2020 \\ (C) Springer Science+Business Media, LLC, part of Springer Nature 2020
}

Correction to: Marine Biotechnology (2019) 21:762-772. https://doi.org/10.1007/s10126-019-09922-w

The original version of this article unfortunately contained a mistake in Fig. 2. The label of the DNA marker used was incorrect. "3000 kb and $1000 \mathrm{~kb}$ " should be corrected to "3000 bp and 1000 bp". The updated Figure is presented below:

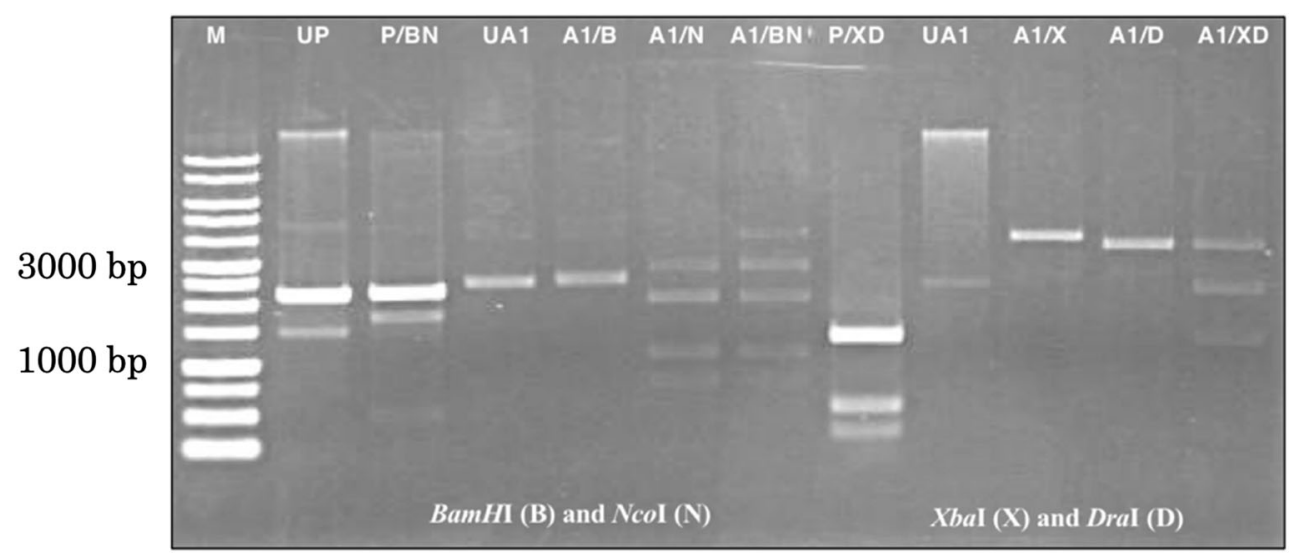

Publisher's note Springer Nature remains neutral with regard to jurisdictional claims in published maps and institutional affiliations.

The original article can be found online at https://oi.org/10.1007/ s10126-019-09922-w

Yoshiko Okamura

okamuray@hiroshima-u.ac.jp

1 Department of Molecular Biotechnology, Graduate School of Advanced Sciences of Matter, Hiroshima University,

Hiroshima, Japan

2 Unit of Biotechnology, Graduate School of Integrated Sciences for Life, Hiroshima University, Hiroshima, Japan 